\title{
Evaluation of the Iraqi Road Safety System in Light of Crash Severity Indicators
}

\author{
Ali A. Aldhalemi ${ }^{1}$, Fadhil A. Abidi ${ }^{2}$ \\ \{alialdhalemi@atu.edu.iq ${ }^{1}$, abidy_fadhil@atu.edu.iq ${ }^{2}$ \} \\ Engineering and Management Technical College/Najaf, Al-Furat Al-Awsat Technical University ${ }^{1,2}$
}

\begin{abstract}
The deaths due to road traffic crashes (RTCs) represent the 8th cause of death in Iraq in 2017 and the 7th cause in 2019. The present work aims to investigate the Iraqi RTCs reports during the years (2006-2019) to evaluate the road safety status and its relationship with the government commitment to reducing fatalities by the year 2020 . The research also presents a quantitative analysis to study the ratios and rates concerning the severity indicators of the crashes and comparing them with some other countries. The results showed that in 2019, each of the crashes, mortalities, and morbidities increased by $21 \%, 5 \%$, and $30 \%$ respectively compared with 2010 and so the governmental commitment appears far-fetched. On the other hand, most of the severity indicators revealed mitigation in the burden of population and motorization during the studied period. The authors concluded that the security situation had a strong impact on road safety and the year 2012 (which came between two waves of terrorist actions) witnessed peak values of crashes, mortalities, and morbidities. Compared with the population and vehicles, the Gross Domestic Product per Capita showed the highest Pearson Correlation Coefficients with each of the crashes, mortalities, and morbidities. Enhancing the road safety system in Iraq is urgently recommended to reduce the numbers of RTCs' casualties in line with the global trend where many countries had reduced the fatalities and now, they are working toward ((Vision Zero)) projects.
\end{abstract}

Keywords: Road safety; Severity indicators; Mortalities; Morbidities, Correlation Coefficient.

\section{Introduction}

The road traffic crash (RTC) is not an ((accident)), and it is completely preventable. So, huge efforts and investments are planned and implemented worldwide to control this humanmade epidemic. According to (The Global Status Report on Road Safety, 2018) issued by the World Health Organization (WHO) [1], there were significant reductions in numbers and rates of RTCs' casualties in Europe and North America but there were no similar results in the rest regions of the world. The report classified Iraq as a middle-income country with an estimated rate of mortalities of 20.7 per 100,000 population based on data of 2016 . Because of many sources of data and different definitions of periods of death after crashes, as well as inaccurate vital registration systems, the WHO report applied an adjustment factor to the number of mortalities reported by the local agencies in each country. Iraq was classified in the fourth group: countries without eligible death registration [2]. According to (The Iraqi Ministry of Health (MoH), Annual Statistical Reports 2017,2019) [3][4], road traffic deaths represent the 8th cause of death in Iraq with a ratio of $(3.47 \%)$ in 2017 and the 7 th cause $(4.9 \%)$ in 2019 . The Iraqi government (in May 2011) had launched "The Decade of Action for Road Safety 20112020" and pledged to reduce the level of road traffic casualties by 2020 [5].

The present work aims to investigate the Iraqi RTCs reports during (2006-2019) to evaluate the results of the countermeasures implemented to meet the Iraqi government commitment. The research also presents a descriptive analysis to study the severity indicators of the crashes and comparing them with some other countries. Besides, the study aims to evaluate the road safety system during the studied period. The present work represents a scientific guide for all central and local authorities, engineers, social activities, and all practitioners who are interested in mitigating road safety problems in Iraq. Statistical Package for Social Sciences (SPSS-V23) was used to compute the correlation between each of the number of crashes, mortalities, and 
morbidities and each of the vehicles, population, and Gross Domestic Product (GDP) Per Capita. Because of the unstable security situation in Iraq after the war of 2003, the Ministry of Planning/Central Statistical Organization (CSO) published ((estimations)) of RTCs data for the years 2002,2003,2004, and 2005 depending on the report of 2001 (CSO Estimates of Traffic Accidents 2004-2005) [6]. However, the CSO report of RTCs 2006 (Statistics of Registered Traffic Accidents 2006) [7] was based on actual records in all governorates of Iraq (except the three governorates of the Kurdistan Iraq Region) and this report seems like a suitable starting point. The RTCs report 2020 issued by the CSO [8] showed a decrease in each crash, mortalities, and morbidity. The year 2020 was an exceptional year due to the full and partial lockdowns that were imposed after the spread of the COVID-19 pandemic, which led to a significant reduction in movement within cities and between governorates. Accordingly, data for the year 2020 were excluded.

\section{Literature review}

The World Health Organization (WHO) in 2013,2015, and 2018 released three comprehensive and detailed reports to describe the global status of road safety. These reports aimed to evaluate the results of the measures implemented in all countries towards achieving the targets of the global Plan for the Decade of Action for Road Safety 2011-2020 and the UN Sustainable Development Goal (SDG) 3.6 to halve the number of casualties by 2020. The Eastern Mediterranean Region (EMR), where Iraq is classified geographically, reported a rate of 18 deaths per 100000 population [1]. The report concluded that except for the EMR, the rate of road traffic mortalities per 100000 population generally decreases as income increases.

To overcome the lack of experts in highway safety and to reduce Road Traffic Crashes (RTCs) in Iraq, Al-Jameel (2016) [9] developed an expert computer system to suit the present status of highway safety. The first phase of the system was the diagnostic phase which identifies the problem and determines probable causes. The second phase was the remedy phase which provides the user with suitable solutions for each probable cause. The author considered the procedure of reporting the RTCs as one of the main problems of the road safety system in Iraq. Leidman et al. (2016) [10] studied the road traffic fatalities in 8 selected governorates in Iraq for the period (2010-2013) depending on data from the Iraqi MoH. The authors concluded that the rates of mortalities ranged from 8.6 to 10.7 per 100,000 population, $80 \%$ of them were males, and nearly half of them were pedestrians. They believed that mortalities decreased in 2013 because of increased insurgency.

Diah et al. (2017) [11] investigated RTCs mortalities in Babil Governorate (middle of Iraq) for the period 2010-2014. They concluded that the peak number of deaths occurred in 2012 and the ratio of males to females was $3.25: 1$. They reported that $72 \%$ of the crashes occurred on the main roads.

Asad (2017) [12] shed light about road safety in Iraq by reviewing the available evidence-based literature concerning traffic crashes during the decade (2005-2015). He surveyed 26 published academic types of research and classified them according to their objectives, data sources, research design, analysis methods, and findings. The retrieved studies had reported that drivers and motorcyclists had low knowledge about traffic signs, not wearing seat belts/or helmets, and driving without licenses.

Mohammed et al. (2018) [13] analyzed data of RTCs in Iraq during (2005-2011) based on the CSO reports of 15 governorates. Among other results, they reported that extreme weather resulted in a higher number of crashes. The authors concluded that Baghdad and Babil governorates witnessed a higher number of collision type crashes while higher ratios of overturning type were recorded in Al- Qadissiya, Baghdad, Babil, and Basrah governorates because of the wetted roads indicating the absence of enough precautions during rainy days. Albayati and Lateif (2018) [14] conducted a descriptive analysis of the road traffic data in Iraq (2003-2015). Based on their results, the run-over crashes accounted for $46 \%$ of the total crashes and collisions accounted for $43 \%$, and males' deaths were four times as often as females. The authors concluded that in each one accident the mortality rate was 0.27 while the morbidity rate was 0.97 . They also reported that statistically there was no ascending or descending trend in the development of the number of crashes for the period (2003-2015).

Al-Jameel et al. (2019) [15] conducted a study about the traffic safety level in Al-Najaf city in the middle of Iraq. They designed a questionnaire form to collect opinions of engineers and engineering students about the causes and solutions of the traffic crashes problem in the city. 
The authors analyzed the responses and concluded that the main causes of crashes in the city refer to the unlicensed drivers on the roads without accounting by the traffic police, vehicles with low safety standards, and poor traffic regulations.

Mohammed et al. (2019) [16] reported that road crashes were relatively high in extreme weather months (August -September, October-November, and December). The authors concluded that the human factor was responsible for $80 \%$ of crashes while each of the roads and the vehicles were responsible for $10 \%$. The researchers recommended that road safety standards in Iraq should include four main factors: exposure, behavioral factors, road environment, and vehicles. Albayati and Lateef (2019) [17] studied RTCs in Baghdad city for the period (2006-2016). They concluded that the run-over crash represented $53 \%$ of all the crashes while the collision and overturning represented $39 \%$ and $7 \%$ respectively. They reported that $27 \%$ of RTCs were associated with people aged 24-29 years, followed by people in the 30-35 age group (22\%), and the 19-23 age group (20\%). The authors concluded that $22 \%$ of RTCs were associated with fatalities, $67 \%$ were associated with only injuries, $6 \%$ included fatal and injury and $4 \%$ included property damage only.

Joni et al. (2020) [18] collected datasets of RTCs in Iraq for the period (2003-2017). They arranged the data of RTCs numbers, mortalities, and morbidities in spreadsheets based on monthly records. The authors observed that the highest monthly rates of crashes, mortalities and morbidities occurred during 2014, 2015, 2016, and 2017 consecutively. They reported that the highest monthly rate during the studied period was $9 \%$ for crashes number, $12 \%$ for morbidities, and $21 \%$ for mortalities. They attributed the increase in the rates during the years (2014-2017) to the bad security condition and absence of safety precaution countermeasures. However, the data used in this research may need more accurate revision.

\section{Data Analysis and Results}

Table 1 summarizes the main data concerning the RTCs in Iraq during the period (2006 2019). Data of population and GDP per Capita were drawn from the website of the World Bank (World Bank Data) [19] while the other data were drawn from the annual reports of The Iraqi Central Statistical Organization (CSO). It can be seen that between 2006 and 2018, the year 2012 witnessed the peak number in each of the crashes, mortalities, and morbidities. In 2019 there were new two peaks in the crashes and morbidities which were slightly higher than the records of 2012. There were continuous annual increases in each of the number of vehicles and population while a peak of (7077) US\$ was noticed in GDP per Capita in 2013.

Table 1. Main data of RTCs in Iraq during the period ( 2006 - 2019).

\begin{tabular}{ccccccc}
\hline Year & Crashes & mortalities & morbidities & Vehicles & Population & $\begin{array}{l}\text { GDP per } \\
\text { Capita (US\$) }\end{array}$ \\
\hline 2006 & 3389 & 1151 & 3303 & 2386612 & 27448124 & 2373 \\
2007 & 3135 & 1210 & 3252 & 2471461 & 27911248 & 3183 \\
2008 & 5502 & 1863 & 5499 & 2491711 & 28385746 & 4637 \\
2009 & 7452 & 2151 & 7955 & 2527335 & 28973162 & 3854 \\
$\mathbf{2 0 1 0}$ & $\mathbf{8 8 6 1}$ & $\mathbf{2 5 0 8}$ & $\mathbf{8 9 9 6}$ & $\mathbf{2 6 6 2 9 4 6}$ & $\mathbf{2 9 7 4 1 9 7 6}$ & $\mathbf{4 6 5 7}$ \\
2011 & 10082 & 2703 & 10198 & 2763667 & 30725300 & 6046 \\
$\mathbf{2 0 1 2}$ & $\mathbf{1 0 7 0 9}$ & $\mathbf{3 1 3 2}$ & $\mathbf{1 1 0 0 9}$ & 3043975 & 31890011 & 6836 \\
2013 & 9725 & 2951 & 10694 & 3527534 & 33157050 & $\mathbf{7 0 7 7}$ \\
2014 & 8814 & 2769 & 9210 & 4239818 & 34411951 & 6819 \\
2015 & 8836 & 2514 & 9429 & 4458780 & 35572261 & 4990
\end{tabular}




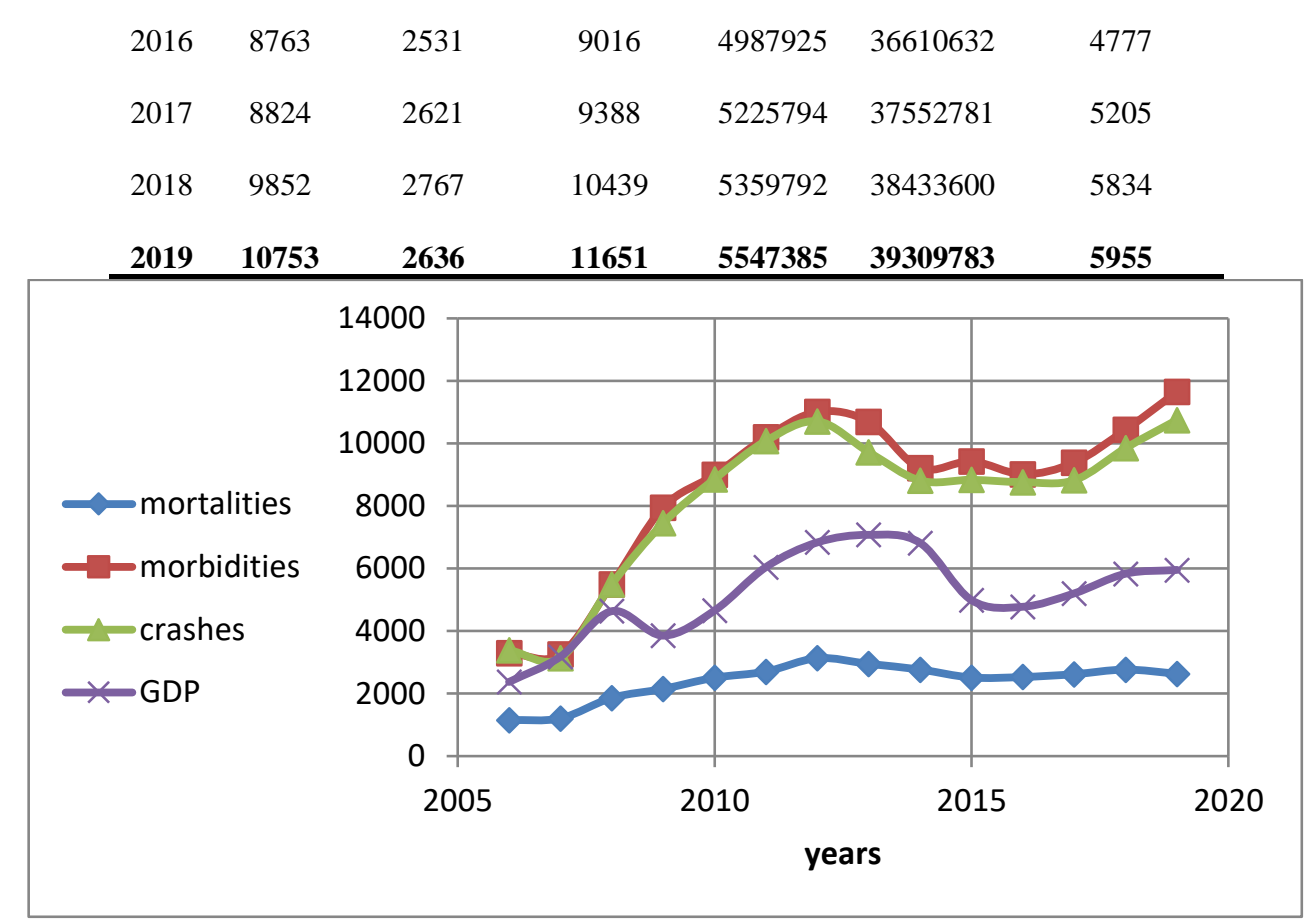

Fig. 1. Annual distribution of crashes, mortalities, morbidities, and GDP per Capita in Iraq (2006-2019).

Table 2. SPSS output of Pearson Correlation Coefficients (PCCs)

\begin{tabular}{|c|c|c|c|c|c|c|c|}
\hline & & Crashes & Mortalities & Morbidities & Vehicles & Population & GDP \\
\hline \multirow[t]{3}{*}{ Crashes } & Pearson Correlation & 1 & $.968^{* *}$ & $.996^{* *}$ & $.564^{*}$ & $.685^{* *}$ & $.850^{* *}$ \\
\hline & Sig. (2-tailed) & & .000 & .000 & .036 & .007 & .000 \\
\hline & $\mathrm{N}$ & 14 & 14 & 14 & 14 & 14 & 14 \\
\hline \multirow[t]{3}{*}{ Mortalities } & Pearson Correlation & $.968^{* *}$ & 1 & $.963^{* *}$ & .514 & $.634^{*}$ & $.915^{* *}$ \\
\hline & Sig. (2-tailed) & .000 & & .000 & .060 & .015 & .000 \\
\hline & $\mathrm{N}$ & 14 & 14 & 14 & 14 & 14 & 14 \\
\hline \multirow[t]{3}{*}{ Morbidities } & Pearson Correlation & $.996^{* *}$ & $.963^{* *}$ & 1 & $.597^{*}$ & $.715^{* *}$ & $.852^{* *}$ \\
\hline & Sig. (2-tailed) & .000 & .000 & & .024 & .004 & .000 \\
\hline & $\mathrm{N}$ & 14 & 14 & 14 & 14 & 14 & 14 \\
\hline \multirow[t]{3}{*}{ Vehicles } & Pearson Correlation & $.564^{*}$ & .514 & $.597^{*}$ & 1 & $.987^{* *}$ & .426 \\
\hline & Sig. (2-tailed) & .036 & .060 & .024 & & .000 & 0 \\
\hline & $\mathrm{N}$ & 14 & 14 & 14 & 14 & 14 & 14 \\
\hline \multirow[t]{3}{*}{ Population } & Pearson Correlation & $.685^{* *}$ & $.634^{*}$ & $.715^{* *}$ & $.987^{* *}$ & 1 & $.543^{*}$ \\
\hline & Sig. (2-tailed) & .007 & .015 & .004 & .000 & & .045 \\
\hline & $\mathrm{N}$ & 14 & 14 & 14 & 14 & 14 & 14 \\
\hline
\end{tabular}




\begin{tabular}{|r|l|l|l|l|l|l|} 
GDP Pearson Correlation & $.850^{* *}$ & $.915^{* *}$ & $.852^{* *}$ & .426 & $.543^{*}$ & 1 \\
& & & & & \\
& & .000 & .129 & .045 & \\
Sig. (2-tailed) & .000 & .000 & .000 & 14 & 14 & 14 \\
$\mathrm{~N}$ & 14 & 14 & 14 & 14
\end{tabular}

**. Correlation is significant at the 0.01 level (2-tailed).

*. Correlation is significant at the 0.05 level (2-tailed).

\subsection{Trend of development}

Fig 1 shows that there are similar trends of development for each of the crashes, mortalities, morbidities, and GDP across the studied period. The T-test statistical technique (Ott, 1989) [20] and (SPSS-V23) computer software was used to determine the type of the development trend for these four variables. The null hypothesis $\left(\mathrm{H}_{\mathrm{o}}\right)$ assumed that there is no descending or ascending trend.

This hypothesis was rejected because the results of the T-test showed 0.000 (2-tailed) significance values for all the four variables which were less than the significance level $(\alpha=$ 0.05). So, it can be concluded that each of the crashes, mortalities, morbidities, and GDP per Capita had an ascending trend of development as shown graphically in Fig 1.

Fig 1 also shows a sharp increase in the number of crashes between (2006-2012) followed by a continuous decrease. This decrease may be attributed to the increased insurgency in 2013 followed by occupying of 3 governorates (Anbar, Salahaldeen, and Nineveh) by ISIS terrorist groups in 2014. Another increase in the number of crashes occurred in 2017 associated with the beginning of liberating the occupied governorates from ISIS groups and a maximum number (10753) was noted in 2019. GDP per Capita showed nearly a similar trend of change during the same periods. GDP per capita increased from 2373 US\$ in 2006 to 7077 US\$ in 2013 and then descended to 4777 US\$ in 2016. GDP per Capita again increased in 2017 and ascended to 5955 US\$ in 2019. On the other hand, the number of vehicles (as well as the population) witnessed a different trend of development than crashes. Table 1 declares that the number of registered vehicles gradually and continuously increased in an ascending trend from 2386612 in 2006 to 5547385 in 2019 and so the motorization level (the number of vehicles per 1000 population) increased from 87 in 2006 to 95 in 2012 and 141 in 2019. The vehicle ownership (persons per vehicle) has decreased from 12 in 2006 to 10 in 2012 and 7 in 2019.

Table 2 displays the output of the SPSS-V23 computer software used to compute the Pearson Correlation Coefficient (PCC) between each of the number of crashes, mortalities, and morbidities, and each of the number of vehicles, population, and GDP per Capita. It can be concluded that the number of crashes has the highest PCC with GDP per Capita (0.850) followed by the population (0.685) and the vehicles (0.564). Table 2 also shows that the mortalities have the highest PCC with GDP per Capita (0.915) followed by the population (0.634) and the vehicles (0.514). The same table shows that the morbidities also have the highest PCC with GDP per Capita (0.852) followed by the population $(0.715)$ and the vehicles $(0.597)$.

Table 3. Severity indicators of RTCs in Iraq (2006-2019).

\begin{tabular}{cccccccc}
\hline Year & $\begin{array}{c}\text { The } \\
\text { ratio of }\end{array}$ & $\begin{array}{c}\text { Rate of } \\
\text { crashes }\end{array}$ & $\begin{array}{c}\text { Rate of } \\
\text { crashes }\end{array}$ & $\begin{array}{c}\text { The ratio } \\
\text { of }\end{array}$ & $\begin{array}{c}\text { Rate of } \\
\text { mortalities }\end{array}$ & $\begin{array}{c}\text { Rate of } \\
\text { mortalities }\end{array}$ & $\begin{array}{c}\text { Rate of } \\
\text { mortalities }\end{array}$ \\
fatal & per & per & mortalities & per 100 & per 10000 & per \\
crashes & 1000000 & 10000 & to total & crashes & vehicles. & 100000 \\
per 100 & population & vehicles. & casualties & & & population \\
crashes & & & & & &
\end{tabular}

\begin{tabular}{llllllll}
\hline 2006 & 28 & 123 & 14.2 & $26 \%$ & 34 & 4.8 & 4.2 \\
2007 & $\mathbf{3 0}$ & 112 & 12.7 & $\mathbf{2 7 \%}$ & $\mathbf{3 9}$ & 4.9 & 4.3
\end{tabular}




\begin{tabular}{llllllll}
2008 & 30 & 194 & 22.1 & $25 \%$ & 34 & 7.5 & 6.6 \\
2009 & 26 & 257 & 29.5 & $21 \%$ & 29 & 8.5 & 7.4 \\
$\mathbf{2 0 1 0}$ & $\mathbf{2 5}$ & $\mathbf{2 9 8}$ & $\mathbf{3 3 . 3}$ & $\mathbf{2 2 \%}$ & $\mathbf{2 8}$ & $\mathbf{9 . 4}$ & $\mathbf{8 . 4}$ \\
2011 & 24 & 328 & $\mathbf{3 6 . 5}$ & $21 \%$ & 27 & 9.8 & 8.8 \\
2012 & 27 & $\mathbf{3 3 6}$ & 35.2 & $22 \%$ & 29 & $\mathbf{1 0 . 3}$ & $\mathbf{9 . 8}$ \\
2013 & 27 & 293 & 27.6 & $22 \%$ & 30 & 8.4 & 8.9 \\
2014 & 29 & 256 & 20.8 & $23 \%$ & 31 & 6.5 & 8.0 \\
2015 & 25 & 248 & 19.8 & $21 \%$ & 28 & 5.6 & 7.1 \\
2016 & 25 & 239 & 17.6 & $22 \%$ & 29 & 5.1 & 6.9 \\
2017 & 27 & 235 & 16.9 & $22 \%$ & 30 & 5.0 & 7.0 \\
2018 & 25 & 256 & 18.4 & $21 \%$ & 28 & 5.2 & 7.2 \\
$\mathbf{2 0 1 9}$ & $\mathbf{2 4}$ & $\mathbf{2 7 4}$ & $\mathbf{1 9 . 4}$ & $\mathbf{1 8 \%}$ & $\mathbf{2 5}$ & $\mathbf{4 . 8}$ & $\mathbf{6 . 7}$ \\
Averag & 27 & 246 & 23.1 & $22 \%$ & 30 & 6.8 & 7.2 \\
\hline
\end{tabular}

\subsection{Severity indicators}

Table 3 has been prepared to compute the severity indicators expressed as ratios and rates during the period (2006-2019).

\subsubsection{Ratio of fatal crashes per 100 total crashes}

The values of this ratio ranged from 24 (2011) to 30 (2006) with an average of 27. The ratio in 2019 (24) was very close to the ratio in $2010(25)$ and there is a (4\%) reduction.

\subsubsection{Rate of crashes per 1000000 population:}

This rate represents the registered number of crashes for each 1000000-population providing us with a fair indicator for the burden of the population. This rate ranged from (112) in 2007 to a maximum (336) in 2012 and then decreased to (274) in 2019. Despite the continuous increase in population from 2006 to 2019, the change in this rate seems like the change in the number of crashes, the number of mortalities, and the number of morbidities when 2012 corresponded to a peak value in each of them. There was a slight reduction $(8 \%)$ in this rate between 2010 (298) and 2019 (274).

\subsubsection{Rate of crashes per 10000 vehicles:}

This rate reveals the burden of vehicles on the number of crashes that occurred annually. The values of this rate ranged from (12.7) in 2007 to (36,5) in 2011 with an average of (23.1). It can be noticed that the peak rate occurred in the year 2011 and there was a reduction of $(42 \%)$ between 2010 (33.3) and 2019 (19.4) which means a lower impact of motorization on the number of crashes.

\subsubsection{Ratio of mortalities to total casualties:}

It is the ratio between the number of mortalities to the total number of human casualties (mortalities and morbidities) which is considered as an important pointer of the severity of crashes. This ratio ranged from $18 \%$ in 2019 to $27 \%$ in 2007 with an average of $22 \%$. Since 2009 the ratio didn't exceed $23 \%$ indicating a slight decrease in severity which may be attributed to better first aids and post-crash care. There was a reduction of $(18 \%)$ in this ratio in 2019 compared with 2010.

\subsubsection{Rate of mortalities per 100 crashes:}


This rate ranged from 25 (2019) to 39 (2007) with an average of 30 for the period (2006-2019). It means that among every 100 crashes in 2019 there were 25 deaths, and this is a very high rate. If all crashes were recorded, including property damage and light injury crashes as in many other countries, the annual number of crashes will be increased and so this rate will be much lower. However, there was a reduction of $(11 \%)$ in this rate in 2019 compared with 2010.

\subsubsection{Rate of Mortalities per 10000 vehicles:}

This rate ranged from $4.8(2006,2019)$ to 10.3 (2012) with an average of 6.8. Despite the rapid and continuous increase in vehicles and motorization levels during the studied period, there was a peak in 2012 and then the rate decreased to 4.8 in 2019. It can be concluded that there was a reduction of (49\%) in this rate in 2019 compared with 2010.

\subsubsection{Rate of Mortalities (per 100000 population):}

Death is the worst impact of any crash, so this rate is widely used globally to compare the severity of traffic crashes between different countries taking into consideration their population. The rate of mortalities per 100000 population from 2006 to 2019 according to the CSO's annual reports were 4.2,4.3,6.6,7.4,8.4,8.8,9.8,8.9,8.0,7.1,6.9,7.0,7.2, and 6.7 respectively. The rate increased from 4.2 in 2006 to a maximum of 9.8 in 2012 then begun to decline and reached 6.7 in 2019. Similar rates were reported by other researchers $[9,13]$, but a much higher rate for AlDiwaniya city (33) was reported by Al-Obaedi (2015) [20]. Table 3 shows a reduction of (20\%) in 2019 compared with 2010.

Table 4. Rates of morbidities during the period (2006-2019)

\begin{tabular}{|c|c|c|c|c|}
\hline Year & $\begin{array}{l}\text { Morbiditi } \\
\text { es to total } \\
\text { casualties }\end{array}$ & $\begin{array}{l}\text { Morbiditi } \\
\text { es per } 100 \\
\text { crash }\end{array}$ & $\begin{array}{c}\text { Morbiditi } \\
\text { es per } \\
10000 \\
\text { vehicles }\end{array}$ & $\begin{array}{c}\text { Morbiditi } \\
\text { es per } \\
100000 \\
\text { populatio } \\
\text { n }\end{array}$ \\
\hline 2006 & $74 \%$ & 97 & 14 & 12 \\
\hline 2007 & $73 \%$ & 104 & 13 & 12 \\
\hline 2008 & $75 \%$ & 100 & 22 & 19 \\
\hline 2009 & $79 \%$ & 107 & 31 & 27 \\
\hline 2010 & $78 \%$ & 102 & 34 & 30 \\
\hline 2011 & $79 \%$ & 101 & 37 & 33 \\
\hline 2012 & $78 \%$ & 103 & 36 & 35 \\
\hline 2013 & $78 \%$ & 110 & 30 & 32 \\
\hline 2014 & $77 \%$ & 104 & 22 & 27 \\
\hline 2015 & $79 \%$ & 107 & 21 & 27 \\
\hline 2016 & $78 \%$ & 103 & 18 & 25 \\
\hline 2017 & $78 \%$ & 106 & 18 & 25 \\
\hline 2018 & $79 \%$ & 106 & 19 & 27 \\
\hline 2019 & $82 \%$ & 108 & 21 & 30 \\
\hline $\begin{array}{l}\text { averag } \\
\mathrm{e}\end{array}$ & $78 \%$ & 104 & 24 & 26 \\
\hline
\end{tabular}

\subsubsection{Rates of morbidities:}

Table 4 summarizes the rates of morbidities in Iraq for the period (2006-2019). The rate of morbidities per 100 crashes ranges from 97 in 2007 to 110 in 2013 with an average of 104. It can be concluded that there is no reduction in this rate between 2010 and 2019 but there was an increase $(6 \%)$ from 102 to 108 . Table 4 also shows that the rate of morbidities per 10000 
vehicles ranged from 13 in 2007 to 37 in 2011. There was a reduction of (38\%) in the rate of morbidities per 10000 vehicles in 2019 compared to 2010. The rate of morbidities per 100000 population ranged from 12 in 2006 and 2007 to a maximum of 35 in 2012 with an average of 26. During the years between 2010 and 2019, there was a fluctuation in the rate of morbidities per 100000 population, but the value (30) was the same in each of 2010 and 2019.

\section{Discussion}

\subsection{Underreporting of Data}

Table 1 shows a total of (114697) crashes occurred in Iraq during the period (2006-2019) with an annual average of (8193). However, the actual numbers are expected to be higher than those recorded by the CSO reports because of underreporting. Reporting a crash in a police station is frequently conducted only when a person is killed, or somebody seriously injured [8]. Even in some of these cases, the relatives of the driver and the victim resort to understanding and agreement, and no lawsuits are registered in the police stations. As for cases of crashes involving light wounds or damage to personal property only, they are usually not recorded in police stations except when the two parties do not agree on a settlement and financial compensation. The police usually record any traffic crash that results in damage to state property to get a fine from the perpetrator and repair the damage. Al-Obaedi (2015) [21] reported that $21 \%$ of traffic crashes are not recorded by the police in Al-Diwaniya city. Underreporting is not limited to the number of crashes only, data reported by the Iraqi $\mathrm{MoH}$ always differ from those published by the CSO which is based on police agencies. For example, in 2019 the Iraqi MoH recorded 4232 deaths because of RTCs [4] while the CSO (as in Table 1) reported 2636 mortalities which were recorded at the scene of the crash (not after 30 days) by the traffic police. For the same year, MoH reported 101709 morbidities while the CSO recorded 11651 only. There is no coordination between the $\mathrm{MoH}$ and the $\mathrm{CSO}$ concerning unifying traffic casualties' data according to international standards. However, underreporting was experienced in many developed and developing countries because of the differences between the hospitals' data and the police records [22,23,24,25].

\subsection{Impact of the Security Status}

The results show that during the period 2006 to 2018, the year 2012 witnessed the peak number of crashes (10709), the peak number of mortalities (3132), and the peak number of morbidities (11009). But 2019 witnessed increases in the number of crashes (10753) and the number of morbidities (11651) compared with 2012. Because of a lack of data concerning total vehicle kilometers traveled each year, no exposure-based interpretation could be presented. However, it can be said that the year (2012) came between two periods of fragile security status after 2003. The first one was between (2003-2007) when terrorist explosions covered most of the Iraqi cities, and the second one was between (2013-2016) when the insurgency increased again, and ISIS terrorist groups occupied three governorates. During the period of a safe security situation (2008-2012), Iraqi people have begun to move and travel making more trips for work, education, entertainment, and internal tourism and there was clear prosperity covering all Iraqi cities associated with high GDP Per Capita. Despite the continuous increase in each of the population and motorization level after 2012, there was a reduction in each of the crashes, mortalities, and morbidities. This reduction may be a result of the second round of terrorism (2013-2016) which affected activities of people day and night resulting in a lower number of trips and less exposure to crashing. We can notice an increase in each of the crashes, mortalities, and morbidities associated with an increase in GDP per Capita during the years (2017- 2019) after the liberation of the three governorates occupied by ISIS terrorists and stability of the security situation. Accordingly, it can be concluded that the security status had a strong impact on the development of RTCs and their casualties in Iraq after 2003.

\subsection{Comparison with Other Countries}

The results show that the lowest ratio of fatalities to total casualties during the studied period was $18 \%$ in 2019. This ratio is considered very high compared with $1 \%$ in each of Sweden, Austria, and Belgium and 5\% in France, and Denmark (United Nations Economic Commission 
of Europe (UNECE), 2017) [26]. However, 2019 witnessed (18\%) reduction in this ratio compared with 2010 and if this reduction continued during the coming years, it will be serious mitigation of the impact of RTCs in Iraq.

As mentioned earlier, WHO adopted a special equation to estimate fatalities based on the data mostly provided by the health agencies rather than police agencies in each country. In Jordan, for example, the official police statistics (The Annual Report of Traffic Accidents in Jordan 2018) [27] reported a rate of mortalities per 100000 population (6.75) for the year 2016 while the rate estimated by WHO was (24.4). When comparing the rate of mortalities per 100000 population of Iraq with the neighboring countries based on WHO Global Report 2018 [1], it can be concluded that the rate of Iraq (20.7) was higher than the global rate (18.2), Turkey (14.5), Kuwait (17.6), and Iran (20.5). On the other hand, it was lower than the rate of Jordan (24.5), Syria (26.5), and Saudi Arabia (28.8). Besides, the average rate of mortalities per 100000 population in the 28 European Union member states (2018) was 4.9 with a reduction of $21 \%$ compared to 2010 (European Commission-Fact Sheet, 2019) [28].

The rate of morbidities per 10000 vehicles in Iraq in 2018 was (19) while the corresponding rates in Jordan, Kuwait, and Saudi Arabia (as computed by the authors) were $(99,50$, and 44) respectively [27,29,30]. In 2018 not only morbidities in Iraq (10439) were lower than those in Jordan (16203) but also several vehicles in Iraq (5359792) were much higher than that in Jordan (1637981). So, it can be concluded that the burden of motorization on traffic morbidities in Iraq is less than that in Jordan.

\subsection{The Governmental Commitment}

According to the previous results, it can be concluded that the commitment launched by the Iraqi government in 2011 to improve road safety and reduce the number of casualties, unfortunately, appears far-fetched. There was no reduction in the number of crashes, mortalities, and morbidities during the period 2010-2019. On the contrary, in 2019, crashes, mortalities, and morbidities were increased by $21 \%, 5 \%$, and $30 \%$ respectively when compared with 2010. On the other hand, there was a reduction in the burden of motorization on each of the crashes (42\%), mortalities (49\%), and morbidities (38\%). Also, there was a reduction in the burden of population on each of the crashes (8\%), and mortalities $(20 \%)$. The rate of morbidities per 100000 population witnessed the same value (30) in each of 2010 and 2019. Besides, there was a reduction $(11 \%)$ in the rate of mortalities per 100 crashes and $(6 \%)$ in the rate of morbidities per 100 crashes.

\subsection{Evaluation of the Road Safety System}

\subsubsection{Legislation}

The traffic law which was applied in Iraq since 2004 (Coalition Provisional Authority, 2004) [31] was not sufficient to achieve the goal of reducing the number of victims because it did not impose fines commensurate with the seriousness of the offense committed, nor did it impose adequate safety measures on drivers or vehicles [12]. Law No. 86/2004 did not specify sufficient conditions for safety when registering vehicles and did not require seat belts, airbags, or anti-lock braking system (ABS) as well as it did not require the wearing of a helmet for a motorcyclist. The law imposed a prison sentence for anyone who drives a vehicle without a license and increased the penalty for anyone who causes harm to others because of recklessness or because of driving under the influence of alcohol or drugs. In 2019, a new traffic law (No.8) was issued by the Iraqi Parliament [32]. The new law imposed high fines for violators and the wearing of a helmet was imposed on motorcyclists. In this law, fines were imposed for using a mobile phone while driving, and children under the age of 8 years were prohibited from sitting in the front seats of the vehicle next to the driver. On the other hand, there was an indulgence in the ages specified for granting driving licenses. The law reduced the penalty for driving without a license, recklessness, or driving under the influence of alcohol or drugs. Many of the severe punishments in this law can be canceled upon the occurrence of concession or compromise between the two quarreling parties. Both Traffic Laws (86/2004 and 8/2019) did not specify the allowable level of alcohol in the driver's blood. (Jindi and Piramis Omar, 2020) [33] have indicated that there is a deficiency and an imbalance in both laws regarding punishments for the crimes of killing and wrongdoing resulting from the traffic crashes. 


\subsubsection{Enforcement}

Despite the existence of the traffic law, researchers $[12,16]$ have noticed that many of its important articles did not find actual application in the street after 2003. The WHO Global Report 2018 recorded low scores for Iraq when assessing its road safety status, especially for the enforcement element. Violations are carried out before the eyes of the traffic policemen without exposure to accountability. The reason may be attributed to the weakness of the security situation and the spread of financial and administrative corruption in the country. So, the people resort to resolve their various disputes (including traffic crashes) away from the judiciary relying on tribal solutions through agreeing on financial compensation apart from the traffic law. The poor performance of the granting license online system resulted in the weak implementation of the law and led to the spread of teenage and even adult drivers without licenses. Drivers generally not followed the instructions of the traffic police such as wearing seat belts, concern for the safety of the vehicle, not exceeding the prescribed speed, avoiding using a mobile phone, children sitting in the vehicle, avoiding driving under the influence of alcohol or drugs, and wearing helmets for motorcycles drivers, and so on. This risky driver behavior may be due to the psychological culture of the society. Many researchers have described the relation between the behavior and socio-cognitive factors like habits, social norms, attitudes, intention, perceived behavior control, and risk perception [34,35,36].

\subsubsection{Reporting and Technology}

A poor safety system begins with poor paper recording forms lacking necessary information like accurate crash details and precise location $[12,16]$. The traffic safety system also suffers from the lack of adopting of modern technologies for monitoring and control like using the Geographic Information System (GIS), the inefficiency of the existing cameras system inside the cities, in addition to the absence of red-light cameras at the intersections or speed cameras (mobile or fixed, hidden or visible) on the roads linking the main cities. The use of speed cameras in Kuwait, for example, has reduced deaths by $15 \%$ (Aljassar et al., 2004) [37]. Boos (2009) [38] reviewed the important role of speed cameras in improving traffic safety, reducing speed, and reducing deaths and injuries in many regions of the world. Besides, traffic police agency, as well as drivers, have little knowledge about Internet and Communication Technology and their applications for better road safety and effective communication with society.

\subsubsection{Infrastructure}

During the studied period there were no effective measures to improve road infrastructures to serve the increasing numbers of vehicles and population. Road's lengths increased from $40755.5 \mathrm{Km}$ in 2006 to $45519 \mathrm{Km}$ in 2018 (Annual Statistical Abstract, 2019) [39] which was not proportional to the increasing number of vehicles and population during this period. There were few additional bridges and grade-separated intersections (or interchanges), no special priorities for public transport, no suitable regulations for trucks, bicycles, motorcycles, and three wheels vehicles. As a general assessment for the road safety status in Iraq, The Global Road Safety Facility (GRSF) hosted by the World Bank reported [40]: "Iraq has a lead agency present, which isn't funded in the national budget. Iraq has a road safety strategy that is also not funded. The functions of the agency include coordination, legislation, and monitoring and evaluation of road safety strategies. The country has no known road safety target." As mentioned previously in the Introduction, the road safety target of Iraq is known but unfortunately, and according to the present results cannot be reached.

\section{Conclusions}

According to the results of the research, the following conclusions could be drawn:

1. There were no reductions in several crashes, mortalities, and morbidities during the decade (2010-2019) despite the mitigation in the burden of each motorization and population. 
2. During the period 2006 to 2018 , the security status had a strong impact on RTCs, and the year 2012 witnessed the peak values in each of the crashes, mortalities, and morbidities.

3. There were similar trends of development for each of the crashes, mortalities, morbidities, and GDP per Capita during the studied period and the general trend was statistically ascending. The GDP per Capita showed the highest Pearson Correlation Coefficients with each of the crashes, mortalities, and morbidities while the population and vehicles showed lower corresponding correlation values.

4. The road safety system needs measures to address the lack in each of legislation, enforcement, reporting, technology, and infrastructure. More effective work is urgently required to reduce numbers of RTCs' casualties in line with the global trend where many countries, after their success in reducing these numbers, are now working toward ((Vision Zero)) projects.

\section{References:}

[1] Global status report on road safety 2018. Geneva: World Health Organization. (2018). https://www.who.int/publications-detail/global-status-report-on-road-safety-2018

[2] Iaych, Dr Kacem, (2017). WHO road safety data collection experience. SafeFITS Round Table, Geneva. http://www.who.int/violence_injury_prevention/en/

[3] Annual Statistical Report 2017, Ministry of Health, Iraq. http://www.moh-planning.com/pdf/2017.pdf

[4] Annual Statistical Report 2019, Ministry of Health, Iraq. https://moh.gov.iq/upload/upfile/ar/1349.pdf

[5] WHO Regional Office for the Eastern Mediterranean, 2011.(accessed on 15-9-2020) http://www.emro.who.int/violence-injuries-disabilities/countries/iraq-roadsafety.html

[6] Statistics of Estimated Traffic Accidents 2004-2005, Ministry of Planning, The Central Statistical Organization, Iraq, 2006.

[7] Statistics of Registered Traffic Accidents 2006, Ministry of Planning, The Central Statistical Organization, Iraq, 2007.

[8] Statistics of Registered Traffic Accidents 2020, Ministry of Planning, The Central Statistical Organization, Iraq, 2021.

[9] Al-Jameel HA. Reducing the number of accidents in Iraq by using expert system. Journal of University of Babylon.2016; 24(4):1099-1112. https://www.iasj.net/iasj/article/116537

[10] Leidman E, Maliniak M, Sultan ASS, Hassan A, Hussain SJ, Bilukha OO. Road traffic fatalities in selected governorates of Iraq from 2010 to 2013: Prospective Surveillance. Conflict and Health.2016; 10(1):2-10. DOI 10.1186/s13031-016-0070-0

[11] Diah B, Baiee HA, AlShalah M. Epidemiological features of road traffic accident deaths in Babylon province during the period 2010-2014. Journal of Babylon University/Pure and Applied Sciences.2017 3(25):1129-1138. https://www.iasj.net/iasj/article/128765

[12] Asad FHA. Road traffic accidents in Iraq: A review of evidence-based literature. International Journal for Traffic and Transport Engineering.2017; 7(2): $256-275 . \quad$ DOI: http://dx.doi.org/10.7708/ijtte.2017.7(2).09.

[13] Mohammed AA, Ambak K, Mosa AM, Syamsunur D. Traffic accidents in Iraq: An analytical study. Journal of Advanced Research in Civil and Environmental Engineering.2018; 5(1\&2):10-22. https://adrjournalshouse.com/index.php/civil-environment-engineering/article/view/169.

[14] Albayati AH, Lateif RH). Statistical analysis of mortality and morbidity due to traffic accidents in Iraq. Journal of Engineering.2018; 1(24): 20-40. https://iasj.net/iasj/download/d4cd89d88f06c63a.

[15] Al-Jameel HA, Abdullah MM, Almosawi BKA. Studying the traffic safety level in Al-Najaf city. Global Journal of Engineering Science and Research Management.2019; 6(2):1-7.

[16] Mohammed AA, Ambak K, Mosa AM, Syamsunur D. A review of traffic accidents and related practices worldwide. The Open Transportation Journal.2019; 13:65-83. DOI: 10.2174/1874447801913010065

[17] Albayati AH, Lateef IM. Characteristics of traffic accidents in Baghdad. Civil Engineering Journal.2019; 5(4): 940-949. https://civilejournal.org/index.php/cej/article/view/1421.

[18] Joni HH, Mohammed AA, Shakir AA. Classification of traffic accidents datasets between 2003-2017 in Iraq. Data in Brief.2020; 28:1-9. https://www.sciencedirect.com/science/article/pii/S2352340919312570.

[19] World Bank Data https://data.worldbank.org/country/iraq (accessed on 20-10-2020).

[20] Ott, L. An introduction to statistical methods and data analysis, $3^{\text {rd }}$ Edition, Boston Mass, USA, PWSKENT Press.1989.

[21] Al-Obaedi JTS. Evaluation of traffic accidents rates in Al-Diwaniya city. Journal of Babylon $\begin{array}{llll}\text { University/Engineering } & \text { Sciences.2015; } & \text { 571-578. }\end{array}$ https://www.iasj.net/iasj/download/d137b1296b0a550f.

[22] Singh P, Lakshmi P, Prinja S, Khanduja P. Under-reporting of road traffic accidents in traffic police records- A cross sectional study from North India. International Journal of Community Medicine and Public Health.2018; 5(2):1-6. DOI:10.18203/2394-6040.ijcmph20180232. 
[23] Watson A, Watson B, Vallmuur K. Estimating under-reporting of road crash injuries to police using multiple linked data collections. Accident Analysis and Prevention.2015; 83:18-25. https://www.sciencedirect.com/science/article/abs/pii/S0001457515300063.

[24] Samuel J C, Sankhulani E, Qureshi JS, Baloyi P, Thupi C, Lee CN, Miller W C, Cairns B A, Charles AG. Under-Reporting of road traffic mortality in developing countries: Application of a capturerecapture statistical model to refine mortality estimates. PLoS ONE.2012; 7(2), e31091. https://doi.org/10.1371/journal.pone.0031091

[25] Reurings MC, Stipdonk HL. Estimating the number of serious road injuries in the Netherlands. Ann Epidemiol.2019; 21(9):648-653. doi:10.1016/j.annepidem.2011.05.007. PMID: 21820630.

[26] United Nations Economic Commission for Europe. Statistics of road traffic accidents in Europe and North America, Volume LIV.2017. https://www.unece.org/fileadmin/DAM/trans/main/wp6/publications/RAS2017.pdf.

[27] The Annual Report of Traffic Accidents in Jordan in 2018. The Public Security Department, Ministry of Interior, Jordan.2019. https://www.psd.gov.jo/images/jti/2018.pdf.

[28] European Commission - Fact Sheet.(2019). Road safety statistics: what is behind the figures?. Brussels. 2018. https://ec.europa.eu/commission/presscorner/detail/en/MEMO_19_1990.

[29] State of Kuwait. Central Statistical Bureau. Statistics of Transportation 2018.https://www.csb.gov.kw/Pages/Statistics?ID=41\&ParentCatID=70

[30] Kingdom of Saudi Arabia. The General Authority for Statistics. Annual Yearbook 2018. https://www.stats.gov.sa/sites/default/files/2018_0.rar.

[31] Coalition Provisional Authority Order Number 86. May 2004.https://govinfo.library.unt.edu/cpairaq/regulations/20040520_CPAORD86_Traffic_Code_with_Annex_A.pdf

[32] The Iraqi Waqai'a. The Official Newspaper of Republic of Iraq. No. 4550.Year 61. 5/8/2019.

[33] Jindi KY, Piramis Omar DA. Legislative treatment of the crime of killing and wrongdoing resulting from traffic accidents. Academic Journal of Nawroz University.2020; 9(3): 290-304. https://doi.org/10.25007/ajnu.v9n3a796.

[34] Meesmann U, Torfs K, Cools M (2020). Socio-cognitive factors in road safety monitoring - cross-national comparison of driving under the influence of Alcohol, drugs or medication. IATSS Research.2020; 44(3):180-187. https://doi.org/10.1016/j.iatssr.2020.09.004.

[35] Chen HYW, Donmez B. What drives technology-based distractions? A structural equation model on social-psychological factors of technology-based driver distraction engagement. Accident Analysis and Prevention.2016; 91:166-174. https://doi.org/10.1016/j.aap.2015.08.015.

[36] Nordfjaern T, Rundmo T, Jørgensen S. A cross-cultural comparison of road traffic risk perceptions, attitudes towards traffic safety and driver behavior. Journal of Risk Research.2011; 14(6): 657-684. doi:10.1080/13669877.2010.547259.

[37] Aljassar AH, Ali MA, Al-Anzi MS). An investigation on the effect of traffic cameras on road safety in Kuwait. 2nd Gulf Road Conference. Paper No. E5.2004. Abu Dhabi. UAE.

[38] Boos MA. Speed cameras as a tool to reduce road fatalities. Virginia Department of Transportation Research Library, Research Synthesis Bibliography No. 23:1-30.2009. https://safety.fhwa.dot.gov/speedmgt/ref_mats/fhwasa1304/resources2/17\%20$\% 20$ Speed $\% 20$ Cameras\%20as\%20a\%20Tool\%20to\%20Reduce\%20Road\%20Fatalities.pdf.

[39] Annual Statistical Abstract (2018-2019) Part 6: Transportation and communications. Ministry of Planning. The central statistical organization. Iraq.2019. http://cosit.gov.iq/ar

[40] The Global Road Safety Facility (GRSF) https://www.roadsafetyfacility.org/country/iraq (accessed on 3-8-2021) 